\title{
Care recipients' physical frailty is independently associated with subjective burden in informal caregivers in the community setting: a cross-sectional study
}

\author{
Thom J. Ringer*, Afeez Abiola Hazzan, Courtney C. Kennedy, Sarah Karampatos, Christopher Patterson, \\ Sharon Marr, Brian Misiaszek, Tricia Woo, George loannidis and Alexandra Papaioannou
}

\begin{abstract}
Background: Physical frailty is associated with significant morbidity and mortality in community-dwelling older adults. Burden in informal caregivers of older adults causes significant physical and psychological distress. However, the relationship between these two clinical phenomena has not been extensively studied. This cross-sectional study evaluated the relationship between physical frailty of community-dwelling older adults attending an outpatient geriatric clinic and the subjective burden reported by their informal caregivers.

Methods: We measured the following characteristics of 45 patient-caregiver dyads attending an outpatient geriatric assessment clinic: Physical frailty using the Fried Frail Scale (FFS); self-reported independence in activities of daily living $(\mathrm{ADL})$ using the Katz Index; clinical diagnosis of dementia; and subjective caregiver burden using the short 12-item version of the Zarit Burden Interview (ZBI). Multivariable linear regression was performed with FFS, Katz Index score, gender, age, and diagnosis of dementia as independent variables, and ZBI score as the dependent variable.
\end{abstract}

Results: Only physical frailty significantly predicted caregiver burden ( $\beta=8.9895 \%$ confidence interval [CI]: 2.15, 15.82). Conclusions: Physical frailty is independently associated with caregiver burden in a population of community-dwelling older adults. Despite limitations related to sample size and lack of data about caregiver characteristics, this study suggests that the relationship between physical frailty and caregiver burden merits further study.

Keywords: Frailty, Physical frailty, Informal caregivers, Caregiver burden, Fried Frail Scale, Zarit Burden Interview, Katz index, Activities of daily living, Functional independence

\section{Background}

It is well-established that providing unpaid care for an ill friend or relative over an extended period of time can impose considerable physical and emotional strain [1]. It has been observed that caregiving has all the features of a chronic stress experience, and is used as a model for studying the health effects of chronic stress [2]. Informal (i.e., unpaid) caregivers of older adults with a range of medical conditions and functional impairments experience significant physical, financial, and psychosocial

\footnotetext{
* Correspondence: thom.ringer@medportal.ca GERAS Centre, Hamilton Health Sciences - St Peter's Hospital Site, 88 Maplewood Avenue, Hamilton, ON L8M 1W9, Canada

hardship, and are at increased risk for psychiatric and medical morbidity $[1,3,4]$.

In the geriatrics literature, caregiver burden has been defined as a multidimensional response to the negative appraisal and perceived stress resulting from taking care of an ill individual [5]. A wide range of instruments exist to measure this response, the most widely used of which is the Zarit Burden Interview (ZBI), a tool based on selfreport [6-8]. The concept of informal caregiver burden has been extensively studied in the settings of dementia, cancer, and stroke [9-11].

Frailty, another prominent concept in the geriatric literature, has been defined as a medical syndrome with multiple causes and contributors that is characterized by 
diminished strength, endurance, and physiologic function that increases vulnerability for developing increased dependency and/or death [12]. Consensus on a definition of frailty remains elusive [13]. Fried and colleagues posit a physical frailty phenotype currently in wide use in research involving five criteria: weight loss, exhaustion, low physical activity, slowness, and weakness [14]. A recent systematic review suggests the syndrome is prevalent among older adults [14]. Physical frailty is significant because it strongly predicts adverse medical outcomes. One study found that physical frailty conferred a mortality hazard ratio of 3.09 , while another concluded that it conferred an odds ratio of 3.3 for disability or mortality $[15,16]$. It is also associated with length of stay and postoperative complications in older patients undergoing surgery [17].

Research to develop interventions targeting frailty is nascent $[18,19]$. Key outcomes of interest have been quality of life, functional status (e.g., ability to perform activities of daily living), depression, and physical function. However, the impact of frailty-reducing interventions on caregiver burden, despite the latter's salience and prevalence, remains relatively unexplored. Indeed, the relationship between frailty and caregiver burden as a whole has received relatively little attention [20].

Given the prevalence and health implications of frailty on the one hand and the physical and psychological burden of informal caregiving on the other, research exploring the relationship between these two phenomena is needed. The objective of this cross-sectional, real world study was to evaluate the relationship between community-dwelling older patients' physical frailty and subjective burden in their informal caregivers.

\section{Methods}

\section{Setting \& participants}

Our study population was a convenience sample of 45 dyads consisting of community-dwelling older adults attending a geriatric outpatient clinic in Hamilton, Ontario, Canada and their informal caregivers. Reasons for referral by the patients' primary care physicians included cognitive impairment, falls, polypharmacy, multimorbidity, and functional decline. All patients attending the clinic received a comprehensive geriatric assessment performed by an interdisciplinary team including a registered practical nurse, case manager, and geriatrician.

All patients attending the clinic between JuneDecember 2013 and July-August 2014 were invited to participate if they were:

1. Deemed fit to participate by a health care professional on assessment at the clinic;

2. Able to follow instructions; and,

3. Accompanied to the clinic by an informal caregiver.
The patient or their legal representative provided informed consent to participate in the study.

\section{Recruitment \& inclusion}

Of the 191 patients attending the clinic, 120 eligible patient-caregiver dyads consented. A further 75 dyads were excluded because the patient resided in a retirement home, and/or a frailty assessment and/or caregiver burden assessment was not completed. The final study sample consisted of 45 patient-caregiver dyads.

\section{Comprehensive geriatric assessment}

Patient demographic and clinical information recorded in the course of the comprehensive geriatric assessment was abstracted (Table 1). This information included the geriatrician's cognitive assessment, including diagnosis of dementia (e.g., Alzheimer's, other, or mixed).

\section{Caregiver burden assessment}

To assess subjective caregiver burden, the accompanying informal caregiver completed the validated short (12item) version of the Zarit Burden Interview (ZBI) [21]. The ZBI yields a score from 0 to 48 , with higher scores indicating a greater degree of burden.

\section{Frailty assessment}

Research assistants assessed patients' physical frailty using the widely used Fried Frail Scale (FFS) criteria:

Table 1 Descriptive characteristics of frail and non-frail subjects

\begin{tabular}{llll}
\hline & $\begin{array}{l}\text { Non-frail } \\
(\mathrm{FFS}<3)\end{array}$ & $\begin{array}{l}\text { Frail } \\
(\mathrm{FFS} \geq 3)\end{array}$ & $\begin{array}{l}\text { Sig. } \\
(2 \text {-tailed })\end{array}$ \\
\hline $\mathrm{N}$ & 27 & 18 & \\
Female gender: $\mathrm{n}(\%)$ & $9(33.3)$ & $13(72.2)$ & 0.010 \\
Mean age: (SD) & $80.5(5.6)$ & $82.9(4.3)$ & 0.122 \\
Mean caregiver ZBI & $13.9(8.6)$ & $20.7(11.4)$ & 0.028 \\
score: (SD) & & & \\
Mean Katz Index (ADL) & $10.7(3.1)$ & $11.1(1.3)$ & 0.606 \\
score: (SD) & & & \\
Marital status: $\mathrm{n}(\%)$ & & & \\
$\quad$ Single & $0(0.0)$ & $1(5.6)$ & 0.225 \\
$\quad$ Married & $17(63.0)$ & $6(33.3)$ & 0.053 \\
$\quad$ Widowed & $3(11.1)$ & $10(55.6)$ & 0.001 \\
$\quad$ Divorced & $3(11.1)$ & $1(5.6)$ & 0.532 \\
$\quad$ Incomplete & $4(14.8)$ & $0(0.0)$ & 0.091 \\
Living arrangement: $\mathrm{n}(\%)$ & & & \\
$\quad$ Alone & $8(29.6)$ & $5(27.8)$ & 0.896 \\
$\quad$ With family & $18(66.7)$ & $10(55.6)$ & 0.463 \\
Other & $0(0.0)$ & $1(5.6)$ & 0.225 \\
Incomplete & $1(3.7)$ & $2(11.1)$ & 0.340 \\
Clinical Diagnosis of Dementia & $14(51.9)$ & $6(33.3)$ & 0.230 \\
\hline
\end{tabular}


reported weight loss of $>10$ lbs in the past year; reported level of exhaustion over the last week; reported physical activity in the past year expressed as average $\mathrm{kcal} /$ week; measured time to walk $4.57 \mathrm{~m}$; and dominant hand grip strength in $\mathrm{kg}$ using a hand-held dynamometer [22, 23]. Patients meeting 3 or more of the FFS criteria (i.e., FFS $\geq 3$ ) were designated as frail. The frail criteria were used as described in the original study by Fried and colleagues [23].

\section{Functional assessment}

Each patient's self- or caregiver-reported ability to perform each of the 6 activities of daily living of the Katz Index of ADLs was recorded [24]. These activities consist of bathing, dressing, toileting, transferring, continence, and feeding. For each activity, a score out of 2 was assigned ( $2=$ needs no help; $1=$ needs some help; 0 = unable to do at all), yielding a total score out of 12 . Lower scores indicated decreased level of independence in activities of daily living.

\section{Analysis}

Univariate and multivariable linear regressions were performed to determine the relationship between physical frailty (FFS $\geq 3$ vs. FFS $<3$ ) of community-dwelling older patients attending an outpatient geriatric clinic and the subjective burden reported by their informal caregivers as measured by ZBI score. Included covariates consisted of age (years), gender, Katz Index of ADLs, and diagnosis of dementia (yes/no).

\section{Results}

\section{Descriptive characteristics}

Of the 45 patients, 18 (40\%) were frail (FFS $\geq 3$ ). Descriptive characteristics of frail and non-frail patients are displayed in Table 1.

\section{Analysis}

Caregiver ZBI scores were 20.7 (11.4) and 13.9 (8.6) for those providing care to frail patients compared with non frail patients, respectively (Table 1 ).

In univariate analysis, frailty was significantly associated with caregiver burden $(\beta=6.80,95 \%$ confidence interval $[\mathrm{CI}] 0.77,12.83$ ) (Table 2). Age, gender, clinical diagnosis of dementia, and Katz Index score were not significantly associated with caregiver burden (Table 2).

In multivariable analysis, frailty was significantly associated with caregiver burden $(\beta=8.979,95 \%$ CI 2.233 , 15.725) (Table 2). Age, gender, clinical diagnosis of dementia, and Katz Index score were not significantly associated with caregiver burden (Table 2).
Table 2 The relationship between a patient's characteristics and caregiver burden

\begin{tabular}{|c|c|c|c|c|c|c|}
\hline & \multicolumn{3}{|c|}{ Multivariate Analysis } & \multicolumn{3}{|c|}{ Univariate Analysis } \\
\hline & \multirow[b]{2}{*}{$\begin{array}{l}\beta \\
\text { coefficient }\end{array}$} & \multicolumn{2}{|c|}{$95 \% \mathrm{Cl}$} & \multirow[b]{2}{*}{$\begin{array}{l}\beta \\
\text { coefficient }\end{array}$} & \multicolumn{2}{|c|}{$95 \% \mathrm{Cl}$} \\
\hline & & Upper & Lower & & Upper & Lower \\
\hline $\begin{array}{l}\text { Frail } \\
(\text { FFS } \geq 3)\end{array}$ & 8.98 & 2.15 & 15.82 & 6.80 & 0.77 & 12.83 \\
\hline Age (years) & -0.09 & -0.71 & 0.53 & 0.04 & -0.56 & 0.65 \\
\hline $\begin{array}{l}\text { Gender } \\
\text { (female) }\end{array}$ & -4.86 & -11.55 & 1.83 & -1.97 & -8.20 & 4.25 \\
\hline $\begin{array}{l}\text { Clinical diagnosis } \\
\text { of dementia (yes) }\end{array}$ & -1.35 & -7.72 & 5.03 & -2.15 & -8.41 & 4.11 \\
\hline $\begin{array}{l}\text { Katz Index (ADL) } \\
\text { score }\end{array}$ & -0.27 & -2.94 & 2.39 & -0.30 & -3.00 & 2.40 \\
\hline
\end{tabular}

\section{Discussion}

Our cross-sectional study of 45 caregiver-recipient dyads attending an outpatient geriatric clinic found that selfreported subjective caregiver burden was higher in those caring for frail patients. Our study also found that caregivers of patients who were diagnosed with dementia did not experience significantly more burden than caregivers of patients without dementia. In contrast to previous studies, we found that a patient's level of independence in ADLs was not significantly associated with increased caregiver burden [5].

\section{Strengths \& Limitations}

Our study is one of the first to directly explore the relationship between physical frailty and caregiver burden using widely used and validated tools to measure each (the FFS and ZBI respectively). Its real world setting - that of a specialized geriatric assessment clinic employing an interdisciplinary care model - also reflects its potential relevance to clinical practice.

Our study findings should be viewed in the context of its design. Our sample size was modest and a larger sample size would increase the statistical power to detect additional factors that may be related to caregiver burden. In addition, our cross-sectional analysis means that causal relationships are difficult to interpret. Reasons for noncompletion of the caregiver burden interview or FFS were not recorded, so selection effect could not be evaluated.

Furthermore, our study considered presence or absence of a diagnosis of any form of dementia, but did not collect information regarding behavioural or psychological symptoms, which have been shown to be more conducive to burden than cognitive deficits [26].

Finally, a recent systematic review has observed that, like many self-reported questionnaires on disability, the Katz Index of ADLs does not cover every essential domain of functioning, disability, and health [25]. Accordingly, the ADL scores used in this study may not reflect aspects of functioning which may bear on caregiver burden. 


\section{Conclusions}

In a real world setting, our study suggests that patient physical frailty may worsen caregiver burden, including associated psychological and physical morbidities. As such, it indicates that future observational and experimental studies addressing physical frailty may benefit from including caregiver burden as a dependent variable. It also provides further support for the observation that "the inclusion of carers in trials targeting frailty may assist in the identification of at-risk carers and facilitate the provision of information and support that will assist them in their role." [27] In addition to addressing some of the limitations discussed above, future studies might be expanded to include analysis of caregiver characteristics or consider support structures. For instance, other studies have shown that caregiver gender, competence, coping and personality traits, and health may affect burden, and that respite care may moderate caregiver burden $[26,28,29]$.

\section{Abbrevations}

ADL: Activities of daily living; FFS: Fried Frail Scale; ZBI: Zarit Burden Interview

\section{Acknowledgements}

None.

\section{Funding}

This study was funded by the GERAS Centre, St. Peter's Hospital, Hamilton, Canada.

\section{Availability of data and materials}

The dataset generated during and/or analyzed during the current study has not been made publicly available as specific participant consent was not requested for such disclosure. Extracts of the data in forms that are fully protective of confidentiality are available from the corresponding author on reasonable request.

\section{Authors' contributions}

TR: Conception and design, study supervision and implementation, analysis and interpretation of data, drafting of the manuscript, critical revision of the manuscript for important intellectual content, final approval of the article. $\mathrm{AAH}$ : Conception and design, study supervision and implementation, analysis and interpretation of data, critical revision of the manuscript for important intellectual content, final approval of the article. CK: Conception and design, study supervision and implementation, analysis and interpretation of data critical revision of the manuscript for important intellectual content, final approval of the article. SK: Conception and design, study supervision and implementation, analysis and interpretation of data, critical revision of the manuscript for important intellectual content, final approval of the article. CP: Conception and design, interpretation of data, critical revision of the manuscript for important intellectual content, final approval of the article. SM: Conception and design, interpretation of data, critical revision of the manuscript for important intellectual content, final approval of the article. BM: Conception and design, interpretation of data, critical revision of the manuscript for important intellectual content, final approval of the article. TW: Conception and design, interpretation of data, critical revision of the manuscript for important intellectual content, final approval of the article. Gl: Analysis and interpretation of data, critical revision of the manuscript for important intellectual content, final approval of the article. AP: Conception and design, interpretation of data, critical revision of the manuscript for important intellectual content, final approval of the article. All authors read and approved the final manuscript.

\section{Authors' information}

TJR: MD Candidate, McMaster University; Research Assistant, GERAS Centre, St. Peter's Hospital, Hamilton, Canada.

AAH: Research Scientist, GERAS Centre, St. Peter's Hospital, Hamilton, Canada.
CK: Associate Scientific Director, GERAS Centre, St. Peter's Hospital, Hamilton, Canada; Research Scientist \& Epidemiologist, GERAS Centre, St. Peter's Hospital, Hamilton, Canada.

SK: Research Assistant, GERAS Centre, St. Peter's Hospital, Hamilton, Canada. CP: Professor, Division of Geriatric Medicine, Department of Medicine, McMaster University, Hamilton, Canada; Chief, Geriatric Services, Hamilton Health Sciences, Hamilton, Canada.

SM: Associate Professor \& Division Director, Division of Geriatric Medicine, Department of Medicine, McMaster University, Hamilton, Canada; Division Director, Division of Geriatric Medicine; Chair, Regional Geriatric Programming, St. Peter's Hospital, Hamilton, Canada; Chair of Aging, St. Peter's Hospital, Hamilton, Canada.

BM: Chief of Geriatric Medicine, Hamilton Health Sciences Centre, Hamilton Ontario; Associate Professor, Department of Medicine, McMaster University. TW: Associate Professor, Division of Geriatrics, Department of Medicine, McMaster University, Hamilton, Canada; Geriatrician, St. Peter's Hospital, Hamilton, Canada.

Gl: Associate Scientific Director, GERAS Centre, St. Peter's Hospital, Hamilton, Canada; Assistant Professor Divisions of Rheumatology \& Geriatrics, McMaster University, Hamilton, Canada.

AP: Professor of Medicine, Department of Medicine, McMaster University; Scientific Director, GERAS Centre, St. Peter's Hospital, Hamilton, Canada; Eli Lilly Canada Research Chair, Canadian Institutes of Health Research.

\section{Competing interests}

The authors declare that they have no competing interests.

\section{Consent for publication}

Not applicable.

\section{Ethics approval and consent to participate}

This study was approved by the Hamilton Integrated Research Ethics Board (REB \#13-344). Written consent was obtained from all participants or their authorized representative.

\section{Note}

An abstract representing an earlier version of this study was presented at the Canadian Geriatrics Society's Annual Scientific Meeting in April 2015, and published in the Canadian Geriatrics Journal. Ringer T, Hazzan AA, Kennedy C, Karampatos S, Patterson C, Misiaszek B, Marr S, Woo T. Frailty predicts degree of caregiver burden in older adults attending a geriatric outpatient clinic. Abstracts from the 35th Annual Scientific Meeting of the Canadian Geriatrics Society, Montreal, Apr. 2015. Can Geriatr J. 2015;18 (3):175 (abst. 17).

Received: 29 November 2015 Accepted: 27 October 2016

Published online: 17 November 2016

\section{References}

1. Bevans MF, Sternberg EM. Caregiving burden, stress, and health effects among family caregivers of adult cancer patients. J Am Med Assoc. 2012;307(4):398-403.

2. Schulz R, Sherwood PR. Physical and mental health effects of family caregiving. Am J Nurs. 2008;108(9 Suppl):23-7.

3. Kim Y, Schulz R. Family caregivers' strains: comparative analysis of cancer caregiving with dementia, diabetes, and frail elderly caregiving. J Aging Health. 2008;20(5):483-503.

4. Vitaliano PP, Zhang J, Scanlan JM. Is caregiving hazardous to one's physical health? A meta-analysis Psychol Bull. 2003;129(6):946-72.

5. Kim H, Chang M, Rose $K$, Kim S. Predictors of caregiver burden in caregivers of individuals with dementia. J Adv Nurs. 2012;68(4):846-55.

6. Deeken JF, Taylor KL, Mangan P, Yabroff KR, Ingham JM. Care for the caregivers: a review of self-report instruments developed to measure the burden, needs, and quality of life of informal caregivers. J Pain Symptom Manage. 2003;26(4):922-53.

7. Zarit SH, Todd PA, Zarit JM. Subjective burden of husbands and wives as caregivers: a longitudinal study. Gerontologist. 1986;26(3):260-66.

8. Graessel E, Berth H, Lichte T, Grau H. Subjective caregiver burden: validity of the 10-item short version of the burden scale for family caregivers BSFC-s. BMC Geriatr. 2014;14:23.

9. Chiao CY, Wu HS, Hsiao CY. Caregiver burden for informal caregivers of patients with dementia: a systematic review. Int Nurs Rev. 2015;62(3):340-50. 
10. Grunfeld E, Coyle D, Whelan T, Clinch J, Reyno L, Earle CC, Willan A, Viola R, Coristine M, Janz T, Glossop R. Family caregiver burden: results of a longitudinal study of breast cancer patients and their principal caregivers. Can Med Assoc J. 2004;170(12):1795-801.

11. Rigby $H$, Gubitz $G$, Phillips $S$. A systematic review of caregiver burden following stroke. Int J Stroke. 2009;4(4):285-92.

12. Morley JE, Vellas B, van Kan GA, Anker SD, Bauer JM, Bernabei R, Cesari M, Chumlea WC, Doehner W, Evans J, Fried LP, Guralnik JM, Katz PR, Malmstrom TK, Mccarter RJ, Gutierrez Robledo LM, Rockwood K, von Haehling S, Vandewoude MF, Walston J. Frailty consensus: a call to action. J Am Med Dir Assoc. 2013;14(6):392-7.

13. Op het Veld LP, van Rossum E, Kempen Gl, de Vet HC, Hajema K, Beurskens AJ. Fried phenotype of frailty: cross-sectional comparison of three frailty stages on various health domains. BMC Geriatr. 2015;15:77.

14. Sternberg SA, Wershof Schwartz A, Karunananthan S, Bergman H, Mark Clarfield A. The identification of frailty: a systematic literature review. Am Geriatr Soc. 2011;59(11):2129-38.

15. Bagshaw SM, McDermid RC. The role of frailty in outcomes from critical illness. Curr Opinion Crit Care. 2013;19(5):496-503.

16. Shamliyan T, Talley KMC, Ramakrishnan R, Kane RL. Association of frailty with survival: a systematic literature review. Ageing Res Rev. 2013;12(2):719-36.

17. Makary MA, Segev DL, Pronovost PJ, Syin D, Bandeen-Roche K, Patel P, Takenaga R, Devgan L, Holzmueller CG, Tian J, Fried LP. Frailty as a predictor of surgical outcomes in older patients. J Am Coll Surg. 2010;210(6):901-8.

18. Lee PS, Lee YS, Chan DC. Interventions targeting geriatric frailty: a systemic review. J Clin Geront \& Geriatr. 2012:3:47e52.

19. Eklund K, Wilhelmson K. Outcomes of coordinated and integrated interventions targeting frail elderly people: a systematic review of randomised controlled trials. Health Soc Care Community. 2009:17(5):447-58.

20. Aggar C, Ronaldson S, Cameron I. Reactions to caregiving in frailty research. Arch Gerontol Geriatr. 2011;53(2):e138-43.

21. Bédard M, Molloy DW, Squire L, Dubois S, Lever JA, O'Donnell M. The Zarit Burden Interview: A new short version and screening version. Gerontologist. 2001:41(5):652-57.

22. Bouillon K, Kivimaki M, Hamer M, Sabia S, Fransson El, Singh-Manoux A, Gale CR, Batty GD. Measures of frailty in population-based studies: an overview. BMC Geriatr. 2013;13:64.

23. Fried $L P$, Tangen $C M$, Walston J, Newman AB, Hirsch C, Gottdiener J, Seeman T, Tracy R, Kop WJ, Burke G, Mcburnie MA. Frailty in older adults: evidence for a phenotype. J Gerontol A Biol Sci Med Sci. 2001;56(3):M14656.

24. Katz S, Downs TD, Cash HR, Grotz RC. Progress in development of the index of ADL. Gerontologist. 1970;10(1):20-30.

25. Yang M, Ding $X$, Dong B. The measurement of disability in the elderly: a systematic review of self-reported questionnaires. J Am Med Dir Assoc. 2014;15(2):150.e1-e9.

26. Adelman RD, Tmanova LL, Delgado D, Dion S, Lachs MS. Caregiver burden: a clinical review. J Am Med Assoc. 2014;311(10):1052-60.

27. Cameron ID, Fairhall N, Gill L, Lockwood K, Langron C, Aggar C, Monaghan N, Kurrle S. Developing interventions for frailty. Advances in Geriatr. 2015; 2015:845356.

28. van der Lee J, Bakker TJ, Duivenvoorden HJ, Dröes RM. Multivariate models of subjective caregiver burden in dementia: a systematic review. Ageing Res Rev. 2014:15:76-93.

29. Mason A, Weatherly H, Spilsbury K, Arksey H, Golder S, Adamson J, Drummond $\mathrm{M}$, Glendinning $\mathrm{C}$. A systematic review of the effectiveness and cost-effectiveness of different models of community-based respite care for frail older people and their carers. Health Technol Assess. 2007;11(15):1-157.

\section{Submit your next manuscript to BioMed Central and we will help you at every step:}

- We accept pre-submission inquiries

- Our selector tool helps you to find the most relevant journal

- We provide round the clock customer support

- Convenient online submission

- Thorough peer review

- Inclusion in PubMed and all major indexing services

- Maximum visibility for your research

Submit your manuscript at www.biomedcentral.com/submit
Biomed Central 